\title{
Fenomenología del embarazo y la ética del aborto'
}

FREDRIK SVENAEUS ${ }^{2}$
Södertörn University

Resumen: En este artículo investigo las maneras en que la fenomenología podría guiar nuestros puntos de vista sobre los puntos a favor y/o en contra del aborto. Por lo que sé, muy pocos fenomenólogos han dirigido su atención hacia este tema, aun cuando algunos se hayan esforzado en comprender y articular mejor los temas estrechamente relacionados al embarazo y al nacimiento, particularmente en el contexto de la filosofía feminista. Después de presentar el debate ético-político actual sobre el aborto, introduzco a la fenomenología en el contexto de la medicina y examino cómo los fenomenólogos han considerado al cuerpo humano como un cuerpo vivido en primera persona por su portador. Luego, me refiero al tema del embarazo y discuto cómo podría aparecer el embrión o el feto para nosotros, particularmente desde la perspectiva de la mujer embarazada, y qué es lo que tal aparecer podría significar desde una perspectiva ética. Se discute cómo la tecnología médica ha transformado la experiencia del embarazo -tanto para la mujer embarazada como para el padre u otras personas cercanas-, particularmente a través la implementación de tempranas detecciones obstétricas de ultrasonido y pruebas de sangre (NIPT) para el síndrome de Down y otros defectos médicos. Concluyo el artículo sugiriendo que la fenomenología

I Publicado originalmente como Svenaeus, Fredrik, (20I7). Phenomenology of Pregnancy and the Ethics of Abortion. Medicine, Health Care and Philosophy. An European Journal 2I (I), 77-87. El traductor desea agradecer al profesor Svenaeus por la autorización para llevarla a cabo. El artículo original es distribuido bajo los términos de Creative Commons Atribution 4.0 International License, que permite su uso irrestricto, distribución y reproducción en cualquier medio mientras que se dé el crédito respectivo a su autor original y a la fuente (http://creativecommons.org/licenses/by/4.0/) (N.d.T).

2 Fredrik Svenaeus es profesor del Centre for Studies in Practical Knowledge en Södertörn University, Suecia. Sus principales áreas de investigación son la filosofía de la medicina, bioética, humanidades médicas y antropología filosófica. Ha publicado una gran variedad de artículos y libros sobre estos temas, la mayoría desde una perspectiva fenomenológica. Extraído de: (https://www.sh.se/p3/ext/content.nsf/aget?openagent\&key=sh_personal_profil_en_577355) (N.d.T). 
puede ayudarnos a negociar un tiempo límite mayor para el aborto legal y, además, proporcionar formas de determinar cuáles son los defectos de embrión-feto que se deben buscar y en qué casos estos deben considerarse como razones suficientes para realizar un aborto.

Palabras clave: ética del aborto, fenomenología, cuerpo vivido, embarazo, ecografía obstétrica, sentir los primeros movimientos fetales, NIPT

Abstract: "Phenomenology of Pregnancy and the Ethics of Abortion". In this article I investigate the ways in which phenomenology could guide our views on the rights and/ or wrongs of abortion. To my knowledge, very few phenomenologists have directed their attention to this issue, although quite a few have strived to better understand and articulate the strongly related themes of pregnancy and birth, most often in the context of feminist philosophy. After introducing the ethical and political contemporary debate concerning abortion, I introduce phenomenology in the context of medicine, and the way phenomenologists have understood the human body as lived and experienced by its owner. I turn then to the issue of pregnancy and discuss how the embryo or fœtus could appear for us, particularly from the perspective of the pregnant woman, and what such showing up would mean from an ethical perspective. The way medical technology has changed the experience of pregnancy-for the pregnant woman, as well as for the father and/or other close ones-is discussed, particularly the implementation of early obstetric ultra-sound screening and blood test (NIPT) for Down's syndrome and other medical defects. I conclude the article by suggesting that phenomenology can help us to negotiate a higher time-limit for legal abortion and, also, provide ways to determine which embryo-fœetus defects to look for, and in which cases these should be looked upon as good reasons for performing an abortion.

Keywords: Ethics of abortion, phenomenology, lived body, pregnancy, obstetric ultrasound, quickening, NIPT

\section{$\S 1$ 1. Introducción}

En este artículo investigo las maneras en que la fenomenología podría guiar nuestros puntos de vista sobre los puntos a favor y/o en contra del aborto. Por lo que sé, muy pocos fenomenólogos han dirigido su atención hacia este tema (Mumford 2013 es una excepción), aun cuando algunos se hayan esforzado en comprender $y$ articular mejor los temas estrechamente relacionados 
al embarazo y al nacimiento, particularmente en el contexto de la filosofía feminista (Adams y Lundquist 2013; Bornemark y Smith 2015; Diprose 2002; Toledano 2016; Young 2005). Después de presentar el debate ético-político actual sobre el aborto, introduciré a la fenomenología en el contexto de la medicina y examinaré cómo los fenomenólogos han considerado al cuerpo humano no sólo como un organismo biológico sino también como un "cuerpo vivido". Luego, me refiero al tema del embarazo y analizo cómo podría aparecer el embrión o el feto para nosotros, enfocándome en la perspectiva de la mujer embarazada que siente los primeros movimientos fetales (quickening) ${ }^{3}$, y qué es lo que tal "aparecer" podría significar desde una perspectiva ética. Se discute cómo la tecnología médica ha transformado la experiencia del embarazo - tanto para la mujer embarazada como para el padre u otras personas cercanas-, particularmente a través la implementación de tempranas detecciones obstétricas de ultrasonido y pruebas de sangre (NIPT ${ }^{4}$ ) para el síndrome de Down y otros defectos médicos. Presento la idea de que las medidas de detección de enfermedades y discapacidades deben realizarse solamente cuando puede predecirse que el bebé por nacer podría llevar una vida considerablemente más dolorosa y alienada, en términos de sufrimiento por la enfermedad, en comparación con una vida humana normal. Concluyo el artículo sugiriendo que la fenomenología puede ayudarnos a negociar un tiempo límite mayor para el aborto legal y, además, proporcionar formas de determinar cuáles son los defectos de embrión-feto que se deben buscar y en qué casos estos deben considerarse como razones suficientes para realizar un aborto, incluso en casos en los que se excede el tiempo límite legal para abortar legalmente en ausencia de defectos detectados.

\section{$\S 2$. La ética del aborto}

La ética del aborto ha sido un campo de batalla desde el surgimiento de la bioética a fines de la década de 1960. Las discusiones sobre lo inadecuado de, o el derecho a interrumpir el embarazo están muy politizadas y cargadas de

3 Con el término quickening el autor alude a los primeros movimientos fetales percibidos por la mujer embarazada (ver el § 5 del presente artículo) (N.d.E).

$4 \quad$ NIPT son las siglas de "non invasive prenatal testing" (pruebas prenatales no invasivas) (N.d.E). 
retórica, especialmente en los EE.UU., pero también en muchos otros países occidentales (Dworkin 1994, cap. 2). El desencuentro entre los pro-vida y los pro-elección es poco menos que total y frecuentemente ha tomado la forma de una guerra entre ideologías religiosas y/o conservadoras frente a ideologías feministas y/o liberales, mientras que en el campo legal se han establecido muchas regulaciones del aborto divergentes en cada país (Warren 2009).

En la postura de los pro-vida se encuentra la idea de que el embrión-feto es una persona desde muy temprano, tal vez incluso desde el primer día. No obstante, las personas son con frecuencia consideradas como criaturas que poseen autoconciencia, lenguaje, memoria y la habilidad de planificar sus acciones, por lo que esta perspectiva no es convincente (DeGrazia 2005, cap. 2). Incluso aceptando el hecho de que los niños, en casos normales, no se desarrollan completamente hasta los 4 o 5 años de edad, e incluso algunos niños (debido a defectos) no lo hacen nunca, no es convincente que se atribuya personalidad a una mera bola de células, aun cuando estas células posean ADN humano. Mucho más persuasiva es la idea de que el embrión-feto merece protección porque es una persona en potencia (Gómez-Lobo 2004). Si bien es difícil negar que por su biología todos los embriones son seres humanos, que sean personas potenciales depende de la manera en que se defina identidad y potencialidad en este escenario (Brown 2007). De acuerdo con el argumento de la potencialidad, la composición genética del embrión dirige su desarrollo desde el inicio, siempre y cuando se le dé la oportunidad de desarrollarse en su entorno natural (el útero de una mujer). Según el argumento pro-vida, el aborto es incorrecto porque termina la vida de una persona (potencial).

En la postura pro-elección se encuentra la idea de que la mujer embarazada tiene el derecho a interrumpir el embarazo, ya que el embrión-feto es una parte de su cuerpo. Las personas tienen el derecho de decidir qué hacer con sus propios cuerpos porque estos les pertenecen. La idea de la autonomía del paciente ha estado en la agenda de la bioética desde su inicio y el derecho al aborto legal de cada mujer ha sido tomado como parte de esta agenda -y la de otros movimientos políticos. Las mujeres tienen el derecho a decidir en temas que conciernen su vida reproductiva, siendo el derecho al aborto legal parte de este grupo de derechos, como también el acceso al control natal o a la fecundación in vitro. De acuerdo con el argumento pro-elección (pro-life), la decisión de continuar o no un embarazo la debe tomar la mujer, 
y no es asunto de nadie más. Si el feto vive o muere es su decisión, al menos hasta cuando este pueda sobrevivir fuera de su cuerpo por la ayuda de una incubadora (Thomson 2006).

¿Puede la fenomenología ofrecer una forma de comprender los dilemas éticos en torno al aborto que pueda resolver el desacuerdo entre la postura pro-vida y la pro-elección? ¿Podría ofrecernos algunos consejos éticos respecto de en qué situaciones el aborto es una elección legítima para una mujer embarazada y en qué situaciones no? Pienso que sí es posible, pero primero se debería hacer una aclaración: realizar un análisis ético-fenomenológico sobre el acto de abortar no es lo mismo que escribir una propuesta de ley. Legítimamente, en la toma de decisiones políticas y en otras áreas de la bioética entran en juego consideraciones que van más allá de los argumentos éticos (Van der Burg 2009). La fenomenología, en cambio, está en condiciones de ofrecer un punto de vista que puede informar mejor a las decisiones políticas, mientras que la creación de leyes puede proveer por sí misma una regulación detallada. Considero que este es el caso de varias contribuciones filosóficas valiosas para la bioética, no solo para la fenomenología. Lo que la fenomenología está en condiciones de ofrecer es una perspectiva que puede hacernos ver las cosas de una forma ligeramente distinta y, espero, más comprensiva en la ética del aborto. Permítanos empezar con una breve introducción sobre lo que significa hacer análisis fenomenológicos sobre cuestiones relativas a la práctica médica y al cuidado de la salud.

\section{§ 3. Fenomenología y medicina}

Hasta ahora, el tema central de la fenomenología de la medicina han sido las experiencias corporales de fenómenos como la enfermedad, el dolor, la discapacidad, el dar a luz y el morir (Meacham 2015; Toombs 200I; Zeiler y Käll 2014). Todos tienen un cuerpo, un cuerpo que puede ser motivo de gran alegría, pero también de gran sufrimiento para quien lo encarna, como bien saben los pacientes y los profesionales de la salud. En este contexto, la cuestión básica en la que el fenomenólogo insistiría es que no solo todos tienen un cuerpo, todos son un cuerpo. No solo me es posible experimentar mi cuerpo propio como un objeto de mi experiencia-cuando lo siento, toco o miro en el espejo-, sino que el cuerpo es lo que primeramente hace posible las experiencias de 
una persona. El cuerpo es mi lugar en el mundo, el lugar donde estoy y que se mueve conmigo, y es también el punto cero que hace posible el espacio y el lugar de las cosas que encuentro en el mundo (Gallagher 2005).

Normalmente, lo que el fenomenólogo llama "el cuerpo vivido" permanece en el trasfondo de nuestra experiencia; nuestra atención, en cambio, se enfoca en las cosas en el mundo y en aquello en lo que estamos involucrados. En las obras de Maurice Merleau-Ponty, para mencionar al más famoso de los "fenomenólogos del cuerpo", encontramos descripciones penetrantes y análisis conceptuales de experiencias cotidianas que son de naturaleza corporal, aunque no estemos enfocados en el cuerpo: ver, escuchar, caminar, hablar, bailar, leer, etc. (Merleau-Ponty 2012). Sin embargo, en algunas situaciones, el cuerpo demanda nuestra atención, lo que nos obliga a tomar nota de su existencia agradable o desagradablemente (Leder 2016; Slatman 2014). Este cuerpo experimentado puede ser la fuente de alegría, como cuando disfrutamos de una buena comida, hacemos deportes, tenemos relaciones sexuales 0 simplemente nos relajamos después de un duro día de trabajo. Sin embargo, el cuerpo puede ser también fuente de grandes sufrimientos para quien lo encarna, ya sea cuando una persona se enferma o se lastima y experimenta dolor, náuseas, fiebre, o cuando tiene dificultades para percibir o moverse (Aho y Aho 2008; Carel 2008).

Cuando me empieza a dar un dolor de cabeza, un ejemplo examinado por Jean-Paul Sartre en El ser y la nada, el fenomenólogo señalaría que el dolor no es solo una sensación experimentada dentro de mi cabeza, sino algo que invade mi entera experiencia del mundo (Sartre 1992; Svenaeus 2015). Si el médico examina mi cuerpo con la ayuda de tecnologías médicas, es posible que detecte los procesos que ocurren en mi cerebro y en el resto del cuerpo que son responsables del dolor de cabeza, pero nunca encontrará mi experiencia, la sensación y el significado que tiene el dolor para mí en mi "estar-en-el-mundo", para hablar en un lenguaje fenomenológico inventado por Martin Heidegger en su obra maestra Ser y tiempo (1996). Esta diferencia entre la perspectiva de la primera y la tercera persona es importante para entender el cuerpo. Hace posible explicar no solo cómo la experiencia humana es simultáneamente concreta y significante, sino también cómo el cuerpo le pertenece a una persona en un sentido más fuerte y más primordial que un par de pantalones, un automóvil o una casa. Una versión fenomenológica de 
la encarnación (embodiment) también es útil para comprender el embarazo y la forma en la que las tecnologías médicas están involucradas en el cuidado de la madre. A estos temas nos referiremos en seguida.

\section{§ 4. Fenomenología y aborto}

Desde el punto de vista fenomenológico, las preguntas relativas a si, cuándo y en qué circunstancias un aborto debe realizarse, tienen que ser discutidas considerando la condición y situación de la mujer embarazada, así como la condición y situación del embrión-feto en sus diferentes etapas de desarrollo en tanto que son reveladas en las experiencias de la mujer embarazada y por medio de investigaciones médicas. Como veremos, el embrión-feto aparece en las experiencias humanas incluso antes de alcanzar una etapa del desarrollo en la que podamos asumir que posee experiencias propias (Bornemark 2015). La diferencia principal entre los puntos de vista fenomenológico y la mayoría de posturas pro-elección sobre el aborto en tal punto es que el cuerpo de la mujer embarazada no es considerado como su propiedad, sino como su modo de ser encarnado (embodied) que pasa por cambios drásticos y significantes en el proceso del embarazo (Mumford 2013). La diferencia principal entre la perspectiva fenomenológica y la de la mayoría de las posturas pro-vida sobre el aborto es que el ser del embrión-feto debe ser considerado desde la perspectiva de la vida de la mujer embarazada desde que este es implantado, y no simplemente como una persona que reside en su cuerpo (Mackenzie 1992; Young 2005). Como veremos, el enfoque en la experiencia corporal del embarazo para formular argumentos sobre el aborto otorga importancia a la forma en que la mujer experimenta la presencia del feto dentro de ella en un determinado momento (quickening) y a las presuntas experiencias del feto en un momento ulterior (sensibilidad). También importa el momento en que el feto puede sobrevivir en una incubadora si el embarazo se interrumpe (viabilidad), porque indica que, al menos desde este momento, se está tratando con dos personas y no sólo con una sola experiencia encarnada.

Al menos dos preguntas diferentes deben ser tratadas en una investigación fenomenológico-ética sobre el aborto. En primer lugar, bajo qué circunstancias y límites de tiempo posibles debe ser permitido por ley y hacer medicamente

I | 2 disponible para una mujer abortar su feto-embrión simplemente porque ella 
así lo desea. En segundo lugar, qué otras circunstancias relacionadas con el embarazo (por ejemplo, por violación, preocupación por la vida de la mujer si el embarazo prosigue) y el estado del feto (defectos médicos) harían razonable extender un límite de tiempo establecido, y en estos casos, cuán lejos debe moverse el punto de referencia.

Permítasenos empezar con la cuestión del aborto legal. Las condiciones y límites para tales posibilidades varían significativamente en las leyes de diferentes países. Y los estándares a menudo han cambiado con el tiempo debido a los cambios en las mayorías políticas. Los países de África, América del Sur y del Sudeste Asiático generalmente no permiten el aborto a excepción de la violación o por razones médicas. Por otro lado, la ley de aborto es frecuentemente más permisible en los países de América del Norte, Europa, el norte y el oeste de Asia, así como en Australia y Nueva Zelanda. Sin embargo, entre los países que permiten el aborto legal, las circunstancias relativas al procedimiento para el consentimiento informado de una mujer pueden diferir. Y tal como está, el tiempo límite del aborto legal varía significativamente de un país a otro, entre 10 a 24 semanas del tiempo de gestación.

¿Qué circunstancias se han tenido en consideración en el proceso político de decidir hasta cuándo una mujer puede decidir sobre el aborto? Generalmente, los países que tienen un marco de tiempo considerablemente extenso (Estados Unidos, Gran Bretaña, Singapur, Suecia, Países Bajos) aluden a los derechos de la mujer individual de hacer lo que le plazca con su propio cuerpo. Mientras que los países que adoptan limitaciones más estrictas (Francia, Finlandia, Dinamarca, Bélgica, Portugal, Vietnam, por dar algunos ejemplos), no lo hacen basándose en los derechos del embrión, sino considerando la perspectiva del embrión-feto en desarrollo (ver mi introducción a la ética del aborto líneas arriba). Esta perspectiva adquiere una gran importancia en las etapas en que se sospecha que el feto siente cosas, como placer o dolor, o si está en condiciones de sobrevivir en una incubadora. La cuestión de cuándo el feto está en condición de sentir dolor es discutida y presentada en los debates políticos en torno al aborto. En consecuencia, no hay consenso científico sobre el tema, aunque la semana 22 parece ser una buena estimación (Bellieni 20I2). Los bebés nacidos en la semana 22, o incluso a fines de la semana 21 , se han salvado en el cuidado neonatal (Edemariam 2007). Pero debe mencionarse que los bebés nacidos antes de la semana 23 rara vez sobreviven y que los 
bebés nacidos muy prematuramente, por regla, padecen de una variedad de graves problemas de salud.

Los medios científicos y tecnológicos para examinar la vida del feto y los inventos que hacen posible que los bebés nacidos prematuramente sobrevivan fuera del útero afectan nuestras opiniones sobre el tiempo límite aceptable del aborto. Si el derecho al aborto se defiende sobre la base de que el feto es parte del cuerpo de una mujer embarazada y nada más, el hecho de que el feto pueda sentir dolor y posiblemente sobrevivir incluso cuando el embarazo se interrumpe parece socavar la opinión de que no es más que una especie de órgano extra que pertenece a la mujer embarazada. No obstante, si el aborto se realiza para salvar la vida de la mujer embarazada o porque las posibilidades de supervivencia del bebé sin defectos graves son mínimas, podría defenderse el derecho (o incluso la obligación) de realizar un aborto en la semana 22 usando estos criterios, en vez de basándose en la idea del "derecho sobre mi cuerpo". Retornaremos sobre el tema de los abortos motivados por motivos médicos a continuación.

\section{$\S 5$. El sentir los primeros movimientos fetales y la alienación corporal}

¿Qué otros momentos del desarrollo en la vida de un feto embrionario, además de la sensibilidad y la viabilidad, deben ser tomados en consideración al establecer el tiempo límite del aborto legal? Desde una perspectiva fenomenológica, la más obvia es la experiencia de la mujer embarazada de "sentir los primeros movimientos fetales" ("quickening") (Bornemark 2015; Young 2005). Las primeras sensaciones del feto moviéndose y pateando en el vientre, por regla general, son sentidas por la mujer embarazada entre las semanas de gestación I8-20 (Sinha et al 20I2,4). En la literatura y en varias páginas web se hallan informes de investigación sobre sensaciones de primeros movimientos fetales incluso más prematuras, así que permítasenos aumentar dos semanas adicionales (semana 16) para estar seguros (probablemente sea muy difícil, si no imposible, en las semanas de gestación anteriores a la semana 16, distinguir movimientos fetales de movimientos intestinales [gases]). 
El sentir los primeros movimientos fetales es un acontecimiento muy significativo porque la mujer puede sentir la presencia de otro ser humano dentro de ella. Este hecho es muy distinto de la experiencia de la alienación corporal en la enfermedad que ha sido analizada por muchos fenomenólogos (cfr. la sección sobre fenomenología y medicina líneas arriba). Drew Leder ha llamado a tal alienación la "des-aparición" ("dys-appearance") del cuerpo en el dolor y en la enfermedad en oposición con la desaparición (disappearance) del cuerpo en el goce cuando el cuerpo permanece en el trasfondo del campo de atención, lo que es su condición normal (Leder 1990, 69). Ciertamente el cuerpo vivido tiene una cierta sensación de este trasfondo todo el tiempo, un modo de estar presente al que podemos enfocar nuestra atención voluntariamente. No obstante, esta manera de sentir las distintas partes del cuerpo, como cuando hacemos lo que es llamado "exploración corporal" en entrenamiento de atención plena (mindfulness), es muy diferente de la fuerza alienante de la des-aparición del cuerpo en el dolor. El cuerpo sano ofrece un modo primordial del estar-en-casa para nosotros, que se convierte en un no-estar-en-casa en la enfermedad (Gadamer 1996; Svenaeus 2009).

Iris Marion Young, quien publicó su libro clásico sobre la fenomenología del embarazoya en 1983, sostiene que las experiencias de embarazo, incluyendo el sentir los primeros movimientos fetales, no son en sí mismas alienantes (Young 2005). Lo que aliena la vida de la embarazada y de la parturienta, según Young, es la óptica médico-tecnológica asociada con el equipo de cuidado materno. La perspectiva de Young es típica de los primeros estudios de fenomenología de la medicina, que toman la perspectiva médica como inevitablemente alienante y por naturaleza opresiva, oponiéndola a una transformación corporal experimentada personalmente que preservaría la dignidad y la autonomía del paciente. En oposición con este punto de vista, sostendría que la ciencia médica y la atención de los médicos y enfermeras no son necesariamente alienantes u opresivos para el paciente (Slatman 2014; Svenaeus 2013). No lo son, ciertamente, cuando las tecnologías médicas ofrecen medios para reducir dolores severos y salvar vidas, como es regularmente el caso en el cuidado materno y el cuidado del parto. Pese a esta crítica, considero que Young y otras académicas feministas están en lo correcto al resaltar los riesgos de medicalizar innecesariamente el embarazo y también al afirmar que el embarazo, pese a involucrar la experiencia de "un extraño", no es por ello necesariamente una experiencia alienante. 
Hay una clara diferencia entre, por ejemplo, las típicas náuseas matutinas al comienzo del embarazo y el sentir los primeros movimientos fetales. Es una diferencia entre las experiencias extrañas del cuerpo vivido, en el caso de la náusea, y experimentar que hay otro ser vivo en mi cuerpo. Hasta cierto punto, el feto puede ser visto como un extraño no querido, particularmente si el embarazo no es deseado, pero en la mayoría de casos, sentir los primeros movimientos del feto es considerado más bien como el primer contacto con el bebé por venir. Sentir al feto es sentir el nosotros (togetherness) de la madre y el niño, y este sentimiento no es normalmente considerado alienante por la mujer embarazada, sino más bien como el sentimiento de un estado de ser distinto y, en cierto modo, más pleno (Bornemark 2015). Muchas feministas que desarrollan argumentos sobre el derecho al aborto legal parecen olvidar, 0 incluso malinterpretar gravemente, las experiencias de la mujer embarazada al retratarlas en forma de un estar ligado a un extraño, cuando más bien se trata de percibir la llegada progresiva del niño. Este no es solo el caso del famoso experimento mental de Judith Jarvis Thomson de despertarse en la cama de un hospital conectado a un violinista inconsciente, quien ha sido conectado a su sistema respiratorio (Thompson 2006), sino también en casos de comparar el feto con, por ejemplo, un pez que ha tomado residencia en el cuerpo de la mujer embarazada (ver las críticas de Mackenzie 1992 y Mumford 2013).

Hay que reconocer que esta manera de intentar especificar las condiciones fenomenológicas del embarazo normal corre el riesgo de subestimar las diferencias individuales entre los embarazos. Si el embarazo no es deseado por la mujer $y$, especialmente, si ha sido provocado por una violación, la mujer embarazada puede sentir que la presencia del feto es alienante por naturaleza. Este puede ser también el caso si la mujer teme por cómo este nuevo modo de ser cambiará su vida, incluso si ella no desea abortar, por ejemplo, si está atemorizada por los dolores de dar a luz o por convertirse en madre. De todos modos, sentir los primeros movimientos del feto puede en ciertos casos servir como una experiencia "contra alienante" en la que la mujer siente el feto y, precisamente por este contacto con el niño, acepte que su embarazo no es completamente algo malo. En cualquier caso, un tiempo límite de 16 semanas de gestación para el aborto legar debería proporcionar suficiente tiempo para abortos legales tempranos en casos en los que las mujeres no deseen continuar con sus embarazos y dar a luz. 


\section{§ 6. La aparición del feto en la ecografía obstétrica}

La experiencia de sentir los primeros movimientos fetales parece ser una fuerte candidata para establecer un límite mayor para el aborto legal desde el punto de vista fenomenológico. Esta idea no es novedosa; de hecho, parece haber proliferado en muchas sociedades pre-modernas y en contextos culturales en los que no se prohibió explícitamente los abortos precoces (Dworkin 1994, $35 \mathrm{ss}$ ). No obstante, las actuales tecnologías médicas han cambiado la forma en que establecemos el primer contacto con el niño en comparación con los tiempos pre-modernos. Como parte rutinaria de la atención obstétrica actual, se hacen imágenes ultrasónicas del feto para determinar una fecha más exacta de la gestación y para buscar signos tempranos de anomalías en el feto, como el síndrome de Down. Las ecografías se realizan rutinariamente en la mayoría de los países desarrollados del mundo en el intervalo gestacional de las semanas 16-20 (y a menudo antes, ver más abajo). Este intervalo de tiempo cuadra bien con los primeros movimientos fetales percibidos por la mujer embarazada.

Son significativas las diferencias entre probar la vida del feto de forma visual o por las sensaciones propias, e incluso podría decirse que las imágenes suministradas en la clínica son más una documentación científica que un contacto con el bebé por venir. No obstante, la rutina de escuchar los latidos del corazón del feto cuando es visto en la pantalla y el suministro de imágenes y videos detallados y realistas ofrecido por los servicios médicos comerciales especializados, contradicen la opinión de que la ecografía es solo una herramienta de diagnóstico médico. De hecho, puede decirse que las imágenes y los videos del feto que se compartirán con los otros y se incluirán en un álbum familiar, se perciben como más reales que lo experimentado al sentir los primeros movimientos fetales, incluso en la perspectiva de la mujer embarazada. La visión, en comparación con otros sentidos (audición, tacto, gusto y olfato) ha sido privilegiada a través de nuestra historia cultural como el último acceso a las cosas en el mundo ("Yo veo"), y esto parece valer incluso en el caso de la ecografía obstétrica y el embarazo. La ecografía "desvela" el cuerpo de la mujer embarazada, brindando una nueva forma de experimentar la presencia del feto para ella y para los demás (Mills 20II, I0I-2I). 
Como se mencionó anteriormente, el diagnóstico de la ecografía se lleva a cabo entre las semanas 16-20 de gestación como parte del cuidado materno estándar. Este intervalo de tiempo encaja bien con los eventos de sentir los movimientos fetales. El contacto tecnológicamente mediado con el feto proporcionado por las imágenes, aunque transforma la experiencia del embarazo, no cambia la opinión sobre el tiempo límite del aborto legal desde un punto de vista fenomenológico. Lo que complica la cuestión de proporcionar un tiempo límite mayor es la reciente introducción, en muchos países, de ecografías más o menos rutinarias en una etapa mucho más temprana del embarazo, aproximadamente entre las semanas 10-12. El motivo de la introducción de estos exámenes es que la ecografía es menos invasiva que las pruebas de ADN fetal para trastornos genéticos. Durante mucho tiempo, tales pruebas se han recomendado en embarazos de alto riesgo (por ejemplo, de madres de edad avanzada), para evaluar si hay síndrome de Down (SD) u otros defectos médicos. Debido a que la muestra de líquido amniótico que contiene ADN fetal requiere la inserción de una aguja en el útero, conlleva cierto riesgo de aborto espontáneo. Las ecografías tempranas fueron introducidas para detectar defectos embrionario-fetales que luego podrían confirmarse o rechazarse por medio de una amniocentesis (y/o pruebas de suero sanguíneo en la madre). Sin embargo, las ecografías tempranas se ofrecen actualmente en algunos países no solo en casos de embarazos de alto riesgo, sino como parte estándar del cuidado maternal (en Dinamarca, por ejemplo). En los países donde se introdujo la ecografía temprana, en combinación con los análisis de sangre de la mujer embarazada, la práctica ha llevado a la realización de un gran número de abortos cuando las pruebas indican un alto riesgo de SD, lo que consecuentemente ha reducido radicalmente el número de bebés nacidos con este defecto (Gordon 2015).

Que una gran cantidad de bebés con defectos cromosómicos u otros defectos congénitos no nazcan porque se considere que las vidas con tales defectos no valgan la pena, y que en consecuencia estas discapacidades se vuelvan raras o inexistentes, puede ser problemático en sí mismo. Nuestra preocupación aquí, no obstante, es cómo las ecografías tempranas afectan nuestros puntos de vista y los argumentos sobre el aborto legal desde el punto de vista fenomenológico. Si la ecografía temprana no se utiliza como una prueba rutinaria en la atención materna, sino solo como una forma de sondear embarazos 
de alto riesgo, no cambia significativamente el análisis que he desarrollado anteriormente. En cambio, si la ecografía temprana se está convirtiendo en parte del cuidado materno estándar y también es presentada por el personal médico como una primera oportunidad para conocer al bebé que vendrá, la fenomenología de las primeras semanas del embarazo sí cambia radicalmente. Que las mismas imágenes hechas en las semanas 10-12 para detectar defectos médicos rutinariamente encuentren su lugar en los álbumes familiares de los posibles padres es tremendamente problemático, si se quiere defender el derecho de las mujeres al aborto legal con un tiempo límite en la semana 16 (que coincide con las primeras experiencias posibles de sentir los primeros movimientos fetales). Admitiendo que algunos padres pueden ver a la ecografía temprana como un procedimiento estrictamente médico (no guardando las imágenes, tal vez ni siquiera mirando la pantalla), lo común es tomarla como una forma de establecer contacto.

El niño por venir aparece para los padres en la ecografía temprana en una etapa del embarazo en la que previamente no era identificable como algo distinto del cuerpo de la mujer. Desde la perspectiva de los médicos, enfermeras y parteras, esto se considera algo positivo, ya que creen que facilita a la mujer asimilar el embarazo y cuidar bien al feto. No obstante, desde la perspectiva del aborto legal, es problemático que algunos fetos en un estadio temprano de su desarrollo sean tomados como significativos éticamente, mientras que otros no sean considerados de esta forma (ya sea por no haber sido examinados 0 porque se hayan abortado a consecuencia de un examen). Esto es claramente ambivalente y la única forma de remediar esta incoherencia es, o poner el tiempo límite del aborto legal en función de la ecografía temprana rutinaria, o aplicar la ecografía temprana solo a embarazos de alto riesgo en lugar de usarlo como forma estándar de establecer contacto con el niño por nacer. Si apuntamos a la primera alternativa, debemos establecer el límite del aborto legal en la misma semana en que se programa dicha prueba en la atención de maternidad. Si apuntamos a la segunda alternativa, la última semana de aborto legal debería ser la primera semana en la que la madre sienta los primeros movimientos fetales. La ley, evidentemente, tiene que establecer una semana específica en vez de referirse a eventos en embarazos individuales. 
Hasta ahora he discutido cómo una perspectiva fenomenológica sobre el embarazo afecta nuestros puntos de vista sobre el aborto legal. Los casos de embarazos que involucran riesgos para la salud de la embarazada abren a una visión permisiva (o incluso cautelar) del aborto en etapas posteriores a las semanas de gestación que han sido discutidas hasta este punto. Si la vida de la mujer se ve en riesgo a causa del embarazo, esta cobra más importancia que la perspectiva del feto que aparece, o incluso que siente, ya que el feto no es una persona, sino solo una persona en potencia (el mismo argumento también podría usarse para casos de violación, en los que la dignidad, más que la vida de la mujer embarazada, se ve amenazada). Las otras razones principales para el aborto por razones distintas a la voluntad de la mujer de no tener un hijo (en el presente) son los defectos embrio-fetales identificados a través de exámenes médicos y pruebas. Dado que parece no solo cruel, sino también inútil ofrecer pruebas de diagnóstico sin la opción del aborto en caso de que resulten positivas, la pregunta ética desafiante se convierte en cuáles son las pruebas que deberían estar disponibles o volverse obligatorias en el cuidado materno, lo que lleva a la cuestión de si, y cómo, elegir las características de los futuros niños.

En su libro El principio de responsabilidad: Ensayo de una ética para la civilización tecnológica, el fenomenólogo Hans Jonas presenta el ejemplo del recién nacido "cuyo mero respirar se dirige de forma incontestable al mundo que lo rodea, es decir, a cuidar de él” (Jonas 1984, 13I). Según Jonas, por su delicadeza el niño recién nacido demanda nuestra atención y asistencia para preservar su vida y permitirle prosperar. El recién nacido manifiesta un llamado ético para asumir la responsabilidad de su ser vulnerable y dependiente, similar al mandato que se origina en el rostro del otro en la ética levinasiana (Levinas 1991). Este mandato apunta a una dimensión temporal apelando a la necesidad de tomar responsabilidad por el futuro y las generaciones venideras (Jonas 1984, 136). El mensaje principal de Jonas en el libro es la necesidad de tomar control de las tecnologías que amenazan el futuro de la vida humana con su potencial para destruir los nichos ecológicos necesarios para la vida en el planeta (por ejemplo, las armas de destrucción masiva, la explotación de los recursos naturales y la contaminación industrial). Sin embargo, su ejemplo I 20 del recién nacido, quien expresa un “tú debes responsabilizarte por mí”, es 
también interesante para el contexto pre-natal, aunque el propio Jonas nunca manifestó una opinión consistente sobre lo correcto o incorrecto del aborto, como sí lo hizo contra la clonación y la mejora genética (Jonas 1987, 162-218).

Como he destacado antes, podría argumentarse que, aunque tal vez más débil, el feto hace un llamado similar a la necesidad a ser cuidado, ya sea apareciéndose a la mujer embarazada que siente los primeros movimientos fetales, 0 tanto a ella como a otros seres cercanos que asumen una responsabilidad en la imagen ultrasónica. Dicho llamado podría poner en cuestión el derecho de la mujer a abortar, así como a otros comportamientos que podrían poner en riesgo la salud y la vida del feto. Sin embargo, ¿qué sucede si el llamado al cuidado entra en conflicto con el conocimiento sobre la situación futura de la madre, o del futuro hijo, que hacen parecer irresponsable continuar el embarazo hasta su fin?

La responsabilidad de asegurar un futuro para el niño cuando la mujer embarazada juzga que sus posibilidades de cuidar bien al recién nacido son escasas o nulas, por razones financieras o de otro tipo, podría ser subsanada por medio de una adopción, lo que implicaría que un cuestionamiento al derecho al aborto en casos de abortos tardíos podría todavía sostenerse desde una óptica fenomenológica. Pero, ¿qué sucede si la predicción tiene que ver con la salud del bebé y la posibilidad de desarrollarse a costa de la madre? Dar conscientemente a luz a un niño con defectos corporales que provocarán un sufrimiento severo y/o una vida radicalmente corta, como es el caso de trastornos como la anencefalia, el síndrome de Edward (trisomía 18), la distrofia muscular, la fibrosis quística o la enfermedad de Tay-Sachs, parece irresponsable e inmoral, al menos si el embarazo pudo ser interrumpido cuando el feto estaba en una etapa no-viable o, mejor aún, previa a sentir sus primeros movimientos (pre-quickening stage). Las pruebas de diagnóstico para tales enfermedades genéticas están disponibles justamente para evitar que los seres humanos futuros padezcan de un sufrimiento innecesario (Milunsky y Milunsky 2016).

Esto no significa que una vida humana con una enfermedad tan grave no sea en todos los casos una vida digna de ser vivida, esto depende de la gravedad del trastorno y de las circunstancias del caso individual, pero sí podría predecirse que sea considerablemente más dolorosa y alienada en términos del sufrimiento por enfermedad de la persona en cuestión. Desde una perspectiva 
fenomenológica, el sufrimiento aparece como un ser-en-el-mundo dolorosamente situado (painfully attuned) ${ }^{5}$ que priva a una persona de sus metas y posibilidades en la vida (Svenaeus 2014). Tal estado de ánimo (mood), o combinación de estados de ánimo, involucra experiencias dolorosas en diferentes niveles conectados, pero que sin embargo se diferencian fundamentalmente: debido, primero, a la encarnación (embodiment) de la persona; segundo, a sus vínculos en el mundo con los otros; $y$, tercero, a los valores centrales de su narrativa de vida. El estar-en-casa o no-estar-en-casa de una persona con un estado de ánimo se interpreta como un ser-en-el-mundo, que también es un ser-como-un-cuerpo y un ser-en-el-tiempo (Heidegger 1996). El sufrimiento, especialmente los sufrimientos causados por la enfermedad, es una experiencia corporal y los poderes alienantes del sufrimiento ocupan un territorio que abarca muchos tipos de problemas del mundo-de-la-vida y de la auto-interpretación.

De acuerdo con ese punto de vista, el sufrimiento es en esencia un sentimiento (un estado de ánimo), pero como tal tiene implicaciones y engloba la vida entera de la persona: cómo actúa en el mundo, cómo se comunica con los demás, cómo comprende y cómo establece sus prioridades y objetivos de vida. Es esencial para la medicina y bioética discernir estas diferentes dimensiones de sufrimiento y cómo están conectadas a través del estado-de ánimo-del-sufrimiento (Svenaeus 2014). Los estados-de-ánimo-del-sufrimiento son típicamente intensos y dolorosos por naturaleza. Sin embargo, también pueden desplegar una cualidad algo subconsciente al presentar las cosas en el mundo y en mi vida como un todo que aparece de modo alienante. Se podría argumentar, desde un punto de vista fenomenológico, que vivir con enfermedades graves como las mencionadas anteriormente hacen doloroso el estado de ánimo de la persona y alienan su vida a tal punto que, si no es peor que nunca haber nacido, al menos es considerablemente peor que normal.

Un argumento a favor del aborto en este contexto puede también incluir los defectos médicos que tienden a empeorar considerablemente la vida humana en comparación con las circunstancias normales, incluso si estos permiten vivir un número largo de años saludables antes de enfrentar a una 
enfermedad dolorosa y mortal (por ejemplo, la enfermedad de Huntington). En tales casos, el sufrimiento será relevante tan pronto como la persona conozca su inevitable decaimiento futuro, y este sufrimiento también abarcará el conocimiento sobre los riesgos de transmitir hereditariamente la enfermedad a los niños. El uso del término "considerable" en el argumento anterior es ciertamente impreciso, pero al menos debería llevarnos a entender las razones que sustentan el aborto, incluso cuando el embarazo se ha desarrollado más allá de las semanas límites que hemos considerado para abortar por razones no médicas. Cuando se puede predecir que el defecto ocasionará un sufrimiento severo y una vida radicalmente acortada al recién nacido, el llamado a la responsabilidad posiblemente se transforme en una obligación de abortar por parte de la mujer a fin de evitar un sufrimiento innecesario a una persona futura (DeGrazia 2005, cap. 7).

\section{§8. Las tecnologías de diagnóstico prenatal y el síndrome de Down}

Las pruebas de diagnóstico que se ofrecen en el cuidado materno analizan el ADN embrio-fetal y otros biomarcadores encontrados en el líquido amniótico (o en la sangre) de la mujer embarazada, así como defectos corporales en la apariencia externa del feto visibles a través de formas de obtención de imágenes como el ultrasonido (Milunsky y Milunsky 2016). Actualmente, la prueba más debatida es la ecografía para detectar el síndrome de Down (SD) mediante el procedimiento NT (Ecografía de Translucencia Nucal), seguida de suero sanguíneo y/o amniocentesis, también llamada "test combinado bioquímicoecográfico" (CUB). El cuestionamiento desde un punto de vista ético de la exploración ultrasónica para detectar elSD se ha enfocado particularmente en la exploración temprana rutinaria más allá de los grupos de riesgo. Recientemente, las posibilidades de detectar trastornos genéticos desde muy temprano en el embarazo por medio del análisis de muy pequeñas cantidades de ADN fetal que se haya en la sangre de la mujer (NIPT) han tomado también el centro de atención (Dondorp et al, 2016). Tales pruebas pueden hacerse para detectar defectos genéticos, o genes asociados a otras características distintas a las enfermedades, muy temprano en el embarazo y con una precisión muy alta. No obstante, dado que los trastornos genéticos son raros, la NIPT puede conducir a un número considerable de falsos positivos, en el caso de que la prueba sea empleada para examinar a la totalidad de mujeres embarazadas y 
no solo a los grupos de riesgo (NIPT es la abreviatura de "pruebas prenatales no invasivas", lo que es potencialmente confuso, ya que se inyecta una aguja para obtener la muestra de sangre de la mujer embarazada; así, el uso del término "no invasivo" en este caso se refiere claramente al cuidado del útero).

El argumento de los que rechazan recomendar como más o menos obligatoria la prueba de diagnóstico temprana para el SD como parte del cuidado materno es que tales pruebas conducen a abortos innecesarios de fetos con riesgo de SD (particularmente cuando se realiza en una etapa temprana del embarazo), lo que es desafortunado porque, primero, los niños pueden no estar afectados (falsos positivos); segundo, porque teniendo el síndrome, pueden llevar una vida buena; $y$ tercero, porque las pruebas y abortos consiguientes (llevados a cabo en aproximadamente el $90 \%$ de los casos positivos) envían el mensaje a las personas con SD y sus familias de que estos niños son una carga innecesaria para la sociedad (Gordon 2015). Además de estas tres preocupaciones, se debe mencionar que el examen prenatal estándar para SD y otros trastornos o enfermedades genéticas podría conducir a una visión menos tolerante en general de las personas que se alejan de la salud normal (healthy norm) en nuestra sociedad en el futuro (Parens 2015).

Reconociendo estos puntos de crítica, se debe tomar en consideración que, aunque una vida con SD no es, por regla general, una vida llena de sufrimiento, es sin duda una vida más afligida por problemas médicos que lo normal, siendo los más frecuentes el riesgo considerablemente mayor de desarrollar insuficiencia cardíaca, trastornos neurológicos, apnea del sueño, problemas del habla, alteraciones endocrinas, enfermedades gastrointestinales y trastornos mentales (Hickey et al, 20I2). También se debe recordar que una vida con SD, incluso si no involucra problemas médicos importantes, está llena de discapacidades intelectuales y estas, en la mayoría de los casos, hacen una vida más corta que otras vidas humanas.

Reconociendo que los problemas médicos son reales y en algunos casos devastadores para la vida de las personas con SD, la perspectiva fenomenológica del sufrimiento y su contraparte emergente, a través de conceptos como estar-en-mundo-dispuesto (cfr. supra), da pie a formas alternativas de llevar una vida no enajenada padeciendo SD. Los objetivos principales de la vida podrían ser diferentes de los comunes y también las narrativas de vida con 
las que las personas con SD se identifican y encarnan junto con familiares y amigos. Si se brindan posibilidades de trabajo y otras actividades significativas, dichas personas podrían desarrollarse y contribuir a nuestra cultura y sociedad de muchas maneras.

El principal problema asociado a juzgar si una vida con SD es considerablemente más propensa al sufrimiento y/o considerablemente menos propensa a desarrollarse que una vida humana "estándar" es que este criterio varía en cada caso. Algunas personas con SD parecen llevar vidas felices y exitosas, mientras que otras sufren o son privadas, a consecuencia del síndrome, de la mayoría de posibilidades que tienen las vidas normales. Las pruebas prenatales no permiten determinar si el niño tendrá una discapacidad grave o un SD de "alto rendimiento". Sin embargo, las pruebas pueden determinar con gran precisión, especialmente si consideramos el ultrasonido en combinación con amniocentesis o NIPT, que el niño sufrirá un SD con complicaciones estándar en algún grado de gravedad desde el primer día de su vida. Esta es una diferencia central en comparación con otras pruebas genéticas (prenatales) que determinan los riesgos estadísticos para el desarrollo de enfermedades en algún momento de la vida, pruebas que ya existen y que probablemente se volverán cada vez más comunes en el futuro junto con la NIPT.

La mayoría de las enfermedades no son trastornos de un solo gen sino multifactoriales, es decir, involucran a muchos genes que determinan los riesgos de desarrollar una enfermedad en combinación con ciertos factores ambientales. Actualmente no aplicamos dichas pruebas de diagnóstico para determinar los riesgos que un niño desarrollará; por ejemplo, enfermedad cardíaca, diversas formas de cáncer, $\mathrm{TDAH}^{6}$ o depresión en algún momento de su vida, debido a que los riesgos asociados con los genes individuales, o incluso con las combinaciones de muchos genes, son muy bajos e inciertos para incentivar el aborto, incluso si las pruebas resultan positivas. Quizás el escaneo ultrasónico para el SD debiese ser considerado más bien como una prueba de bajo riesgo en razón de que lo que la prueba debería determinar en realidad como relevante es el riesgo de desarrollar SD con problemas médicos graves y con severas discapacidades intelectuales, y no el SD en 
cuanto tal. Que la prueba de diagnóstico actual se considere relevante o no depende del tamaño del grupo de personas SD con sufrimiento severo en comparación con el tamaño del grupo de SD con leves padecimientos. Si la relación fuese de 20-80, probablemente no deberíamos utilizar la prueba NT como un procedimiento estándar del cuidado maternal. Si la relación es más cercana al 80-20, el riesgo de sufrir SD severo es probablemente muy alto como para no ofrecer la prueba como parte del cuidado materno rutinario. Actualmente no puedo hacer la estimación, pero creo que esta sería la mejor manera de abordar la ética del diagnóstico prenatal para el SD. Al realizar tal estimación, debe tenerse en cuenta que en una perspectiva fenomenológica los estados de ánimo o incluso los estados de ánimo alegres, o el hecho de que las personas con SD parecen estar normalmente alegres, claramente cuenta en contra de considerar la vida tan llena de sufrimiento, incluso si formas importantes del desarrollo puedan estar negadas a consecuencia de las discapacidades intelectuales (Svenaeus 2014).

\section{§ 9. La mirada médico-tecnológica}

¿Sería suficiente una proporción del 50-50 para motivar la evaluación del SD en el embarazo temprano? Quizá, pero mucho depende de qué criterios se establecen para los dos grupos de SD, leve y grave. Estaríamos inclinados a ver más proporción de riesgo y discusiones sobre la gravedad de una variedad de enfermedades en el futuro si el NIPT es implementado en los embarazos tempranos como parte estándar del cuidado materno. Dado que tales riesgos, vinculados a ciertos genes, también pueden, en algunos casos, ser "riesgos" para desarrollar características que apreciamos, ya sea la sensibilidad emocional o inteligencia en el caso de la depresión y del trastorno bipolar, por dar un ejemplo, esta es una vía que debería ser supervisada de cerca y éticamente escudriñada. Una implementación difundida del NIPT podría llevar a un mayor número de abortos realizados con el fin de evitar dar a luz a bebes con riesgos de desarrollar enfermedades $y / o$ tener defectos genéticos de diversos tipos. Tal vía es éticamente problemática por las diferentes razones que he abordado antes: abortos de falsos positivos, abortos de embriones-fetos que podrían haber dado lugar a personas cuyas vidas no hubiesen sido considerablemente peores que las normales, estigmatizar a las personas que viven 
con las enfermedades y trastornos, y una visión menos tolerante en general sobre las anormalidades en nuestra sociedad.

Sin embargo, reemplazar la ecografía temprana para el SD solo por el NIPT tendría una ventaja significativa a la luz del argumento fenomenológico sobre el aborto desarrollado anteriormente. El embrión-feto examinado a través de NIPT no se mostraría a los padres en la forma en que lo hace la imagen en movimiento del feto en la pantalla y no daría lugar a ninguna fotografía de álbum familiar. La prueba de sangre no provocaría ningún contacto con un niño, tal como lo hace actualmente la ecografía, sino que más bien sería un examen médico-tecnológico del cuerpo de la embarazada. No obstante, no se debe subestimar la forma en que las tecnologías médicas, también en los casos que no dan lugar a imágenes espectaculares, pueden transformar nuestra percepción y formas de pensar sobre lo que importa en la vida humana y sobre lo que es normal. Cada vez más nos convertimos en objetos de una mirada médico-tecnológica que estamos haciendo nuestra. Heidegger, en la década de 1950, llamó a esto “Gestell", una imagen de nuestro mundo dada por la ciencia en la que todo se muestra como calculable y utilizable (Heidegger 1977). Heidegger, en sus ensayos sobre tecnología, se refirió principalmente a que los bosques, ríos y la tecnología nuclear están sometiéndonos a la Gestell, pero la verdadera extensión de su análisis son los recientes desarrollos de la tecnología genética, en los que la humanidad misma está tornándose la manipulada, y no solo el manipulador (Svenaeus 2013). La ecografía temprana también podría verse como una imagen del mundo, la cual transforma el embarazo en la producción de bebés normales, aunque el significado y el uso cultural sean sin duda mucho más extenso que este, como lo mencioné anteriormente.

Es obvio que muchas tecnologías médicas, si se emplean y se mantienen dentro de los límites del buen juicio y uso, son demasiado valiosas para nuestras vidas como para abstenernos de ellas, aunque obliguen a las personas a tomar una posición y posiblemente cambiar sus actitudes hacia sus propias vidas y cuerpos (Svenaeus 2013). Pese a ello, en el caso del embarazo el impacto de la tecnología médica no solo ha consistido en hacer que el embarazo y el parto sean más seguros para la madre y el niño, sino que también implica un impacto en la relación desarrollada con el feto-embrión y los riesgos de instrumentalizar las cuestiones relativas a la reproducción humana. Si se eligen 
los niños o más bien no se eligen en el caso del SD, debido a sus genes en lugar de ser tomados como personas en un sentido potencial, esto podría tener consecuencias negativas en la relación padre-hijo como tal (Habermas 2003; Hauskeller 2014; Parens 2015). Este es un tema importante en los estudios sobre "mejora humana", pero un análisis fenomenológico de la relación padrehijo y su transformación a través de futuras tecnologías médicas que permiten diseñar bebés está fuera del alcance de este artículo.

\section{$\S 10$. Conclusiones}

El análisis fenomenológico en el campo de la ética del aborto procede de la perspectiva corporal de la mujer embarazada y de la perspectiva imaginaria del embrión-feto-recién nacido, conocida a través de la ciencia médica y las tecnologías. La principal diferencia entre los puntos de vista fenomenológico y la mayoría de pro-elección sobre el aborto es que en tales análisis el cuerpo de la mujer embarazada no es considerado como su propiedad, sino como un modo de ser encarnado (embodied) que pasa por cambios drásticos y significantes en el proceso de embarazo. La diferencia principal entre los puntos de vista fenomenológicos y la mayoría de las posturas pro-vida sobre el aborto es que el ser del embrión-feto debe ser considerado desde la perspectiva de la vida de la mujer embarazada, y no simplemente como una persona-existente que reside en su cuerpo.

La experiencia de sentir los primeros movimientos fetales aparece como una razón importante desde el punto de vista fenomenológico para establecer un tiempo límite para el aborto legal, alrededor de la semana 16 del tiempo de gestación. En los primeros movimientos fetales, la mujer embarazada siente la presencia de otro ser humano dentro de ella y esto, por lo general, no es un evento alienante, sino parte y proceso de un modo diferente de ser encarnado (embodied being), en contacto con un niño por venir, que demanda protección y apoyo. En los casos de poder evitar dar a luz a niños que sufrirán vidas mucho más dolorosas y alienadas de lo normal, la responsabilidad de cuidar al niño se transformará en la responsabilidad de considerar y/o tener un aborto; también en los casos de embarazos que continúan más allá de las semanas en las que se empiezan a sentir los primeros movimientos fetales 
o, incluso, en algunos casos, más allá de las semanas en las que los fetos son capaces de sentir y son viables.

Las tecnologías de diagnóstico, como la ecografía y diversas formas de pruebas genéticas, no solo hacen posible abstenerse de tener hijos que sufrirán vidas mucho más dolorosas y alienadas de lo normal, sino que también transforman la experiencia del embarazo en cuanto tal. El feto aparece a la mujer embarazada y a otros a través de imágenes de ultrasonido, videos y sonidos, en algunos casos mucho antes de que se dé a conocer a través de los primeros movimientos fetales. Esto debe tenerse en cuenta al establecer mayores límites de tiempo para el aborto legal.

En el caso del síndrome de Down (SD), las pruebas tempranas mediante el procedimiento NT, seguidas de suero sanguíneo y/o amniocentesis $y$, en el futuro, el NIPT, ya tienen y probablemente tengan como consecuencia que haya cada vez menos y menos niños que nazcan con SD. Tal camino es éticamente cuestionable por las siguientes razones: abortos de embriones-fetos que habrían dado lugar a personas con vidas que no son considerablemente peores de lo normal según un análisis fenomenológico; efectos estigmatizadores para las personas que padecen SD; y una visión menos tolerante, en general, ante las anormalidades en nuestra sociedad. La última consecuencia es una clara indicación de que las tecnologías médicas no solo nos brindan más opciones con respecto a qué tipo de niños deberían nacer, sino que también cambian nuestra percepción de lo que es una vida humana normal y qué es lo que, en principio, se considera una vida digna.

Traducción de Raphael Aybar 


\section{Bibliografía}

Adams, S. LaChance y C.R. Lundquist (eds.), 2013. Coming to Life: Philosophies of Pregnancy, Child Birth and Mothering. Nueva York: Fordham University Press.

Aho, J., y Aho, K., 2008. Body Matters: A Phenomenology of Sickness, Disease, and IIlness. Lanham: Lexington Books.

Bellieni, C.V., 2012. Pain assessment in human fetus and infants. The AAPS Journal 14 (3), 453-46I.

Bornemark, J., 20I5. Life beyond Individuality: A-subjective Experience in Pregnancy. En Phenomenology of Pregnancy, eds. J. Bornemark y N. Smith. Huddinge: Södertörn Philosophical Studies.

Bornemark, J. y N. Smith (eds.), 2015. Phenomenology of Pregnancy. Huddinge: Södertörn Philosophical Studies.

Brown, M.T., 2007. The Potential of the Human Embryo. Journal of Medicine and Philosophy 32, 585-618.

Carel, H., 2008. Illness: The Cry of the Flesh. Stocksfield: Acumen Publishing.

DeGrazia, D., 2005. Human Identity and Bioethics. Cambridge, Mass.: Cambridge University Press.

Diprose, R., 2002. Corporeal Generosity: On Giving with Nietzsche, Merleau-Ponty, and Levinas. Albany: State University of New York Press.

Dondorp, W.J., G.C. Page-Christiaens y G.M. de Wert, 2016. Genomic Futures of Prenatal Screening: Ethical Reflection. Clinical Genetics 89 (5), 53I-538.

Dworkin, R., 1994. Life's Dominion: An Argument about Abortion, Euthanasia, and Individual Freedom. Nueva York: Vintage Books.

Edemariam, A., 2007. Against all Odds. The Guardian, February 21.

Gadamer, H.-G., 1996. The Enigma of Health: The Art of Healing in a Scientific Age. Stanford: Stanford University Press.

Gallagher, S., 2005. How the Body Shapes the Mind. Oxford: Oxford University Press.

Gómez-Lobo, A., 2004. Does Respect for Embryos Entail Respect for Gametes? Theoretical Medicine and Bioethics 25, 199-208.

Gordon, O., 2015. Living with Down's Syndrome: He's Not a List of Characteristics. He's My Son. The Guardian, October 17. 
Habermas, J., 2003. The Future of Human Nature. Cambridge: Polity Press.

Hauskeller, M., 20I4. Better Humans? Understanding the Enhancement Project. Londres: Routledge.

Heidegger, M., 1977. The Question Concerning Technology and other Essays. Nueva York: Harper \& Row.

— 1996. Being and Time. Albany: State University of New York Press.

Hickey, F., E. Hickey y K.L. Summar, 20I2. Medical Update for Children with Down Syndrome for the Pediatrician and Family Practitioner. Advances in Pediatrics 59 (I), I37-I57.

Jonas, H., 1984. The Imperative of Responsibility. In Search for an Ethics for the Technological Age. Chicago: Chicago University Press.

- 1987. Technik, Medizin und Ethik. Frankfurt am Main: Suhrkamp Verlag.

Leder, D., 1990. The Absent Body. Chicago: University of Chicago Press.

- 2016. The Distressed Body: Rethinking IIIness, Imprisonment and Healing. Chicago: University of Chicago Press.

Levinas, E., 199I. Totality and Infinity. Dordrecht: Kluwer.

Mackenzie, C., 1992. Abortion and Embodiment. Australian Journal of Philosophy 70 (2), I36-155.

Meacham, D., (ed.), 20I5. Medicine and Society, New Perspectives in Continental Philosophy. Dordrecht: Springer.

Merleau-Ponty, M., 2012. Phenomenology of Perception. Londres: Routledge.

Mills, C., 20II. Futures of Reproduction: Bioethics and Biopolitics. Dordrecht: Springer.

Milunsky, A. y J. Milunsky (eds.), 2016. Genetic Disorders and the Fetus: Diagnosis, Prevention, and Treatment. Hoboken: John Wiley.

Mumford, J., 2013. Ethics at the Beginning of Life: A Phenomenological Critique. Oxford: Oxford University Press.

Parens, E., 2015. Shaping Ourselves: On Technology, Flourishing, and a Habit of Thinking. Oxford: Oxford University Press.

Sartre, J.-P., 1992. Being and Nothingness: A Phenomenological Essay on Ontology. Nueva York: Washington Square Press.

Sinha, S., L. Mially L.Jardine, 2012. Essential Neonatal Medicine. Chichester:John Wiley. 
Slatman, J., 2014. Our Strange Body: Philosophical Reflections on Identity and Medical Interventions. Amsterdam: Amsterdam University Press.

Svenaeus, F., 2009. The Phenomenology of Falling III: An Explication, Critique and Improvement of Sartre's Theory of Embodiment and Alienation. Human Studies 32. 53-66.

- 2013. The Relevance of Heidegger's Philosophy of Technology for Biomedical Ethics. Theoretical Medicine and Bioethics 34 (I), I-I6.

- 2014. The Phenomenology of Suffering in Medicine and Bioethics. Theoretical Medicine and Bioethics 35 (6), 407-420.

-20I5. The Phenomenology of Chronic Pain: Embodiment and Alienation. Continental Philosophy Review 48 (2), 107-122.

Thomson, J.J., 2006. A Defense of Abortion. En: Bioethics: An Anthology, eds. H. Kushe y P. Singer. Oxford: Blackwell, 25-4I.

Toledano, S.J., 2016. Sharing the Embodied Experience of Pregnancy. En: Bodily Exchanges, Bioethics and Border Crossing: Perspectives on Giving, Selling and Sharing Bodies, eds. E. Malmqvist y K. Zeiler. Londres: Routledge, I02-II8.

Toombs, S.K. (ed.). 200I. Handbook ofPhenomenology and Medicine. Dordrecht: Kluwer.

Van der Burg, W., 2009. Law and Bioethics. En: A Companion to Bioethics, eds. H. Kushe y P. Singer. Oxford: Blackwell, 56-64.

Warren, M.A., 2009. Abortion. En: A Companion to Bioethics, eds. H. Kushe, y P. Singer. Oxford: Blackwell, I40-I48.

Young, I.M., 2005. Pregnant Embodiment: Subjectivity and Alienation. En: On Female Body Experiences. Oxford: Oxford University Press, 46-6I.

Zeiler, K. y L. Folkmarson Käll (eds.), 2014. Feminist Phenomenology and Medicine. Albany: State University of New York Press. 